J. Lake Sci. (湖泊科学), 2006, 18(5) :495-498

http:// www. jlakes. org. E-mail: jlakes@ niglas. ac.cn

(c) 2006 by Journal of Lake Sciences

\title{
风浪扰动对太湖水体悬浮物重金属含量的影响“
}

\author{
池俏俏 $^{1,3}$, 朱广伟 ${ }^{1 * *}$, 张战平 ${ }^{2}$, 秦伯强 ${ }^{1}$ \\ (1: 中国科学院南京地理与湖泊研究所, 南京 210008) \\ ( 2 : 浙江大学环境与资源学院, 杭州 310029$)$ \\ (3: 中国科学院研究生院, 北京 100039)
}

摘 要: 通过离心浓縮的方法, 获取太湖梅梁湾口东岸处 (即梅梁湾与贡湖湾的交界处) 不同风浪条件下的悬浮颗粒物, 冷冻干燥, 微波消解, ICP-AES 的方法测定了其中 $\mathrm{Co} 、 \mathrm{Cr} 、 \mathrm{Cu} 、 \mathrm{Ni} 、 \mathrm{~Pb} 、 \mathrm{Zn}$ 等重金属元素及 $\mathrm{Al} 、 \mathrm{Ca} 、 \mathrm{Fe} 、 \mathrm{Mn}$ 等相关金属元素的 含量. 结果发现, 小风浪 $(2 \mathrm{~m} / \mathrm{s}) 、$ 、浪 $(7 \mathrm{~m} / \mathrm{s})$ 和大风浪 $(11 \mathrm{~m} / \mathrm{s})$ 下: (1)水体总悬浮颗粒态金属的量依次大幅度增加; (2) 单位悬浮颗粒物中各金属元素的含量在不同风浪下变化不同. Ca 在小、中、大风浪下含量依次增大; Zn 在小、中、大风浪 下含量依次减少; $\mathrm{Mn}$ 和 $\mathrm{Cu}$ 的含量变化趋势相同: 与小风浪相比, 中风浪下 $\mathrm{Mn} 、 \mathrm{Cu}$ 的含量显著增大; 与中风浪相比,大风 浪下含量显著减少; 其它元素 $\mathrm{Al} 、 \mathrm{Fe} 、 \mathrm{Ni} 、 \mathrm{~Pb} 、 \mathrm{Co} 、 \mathrm{Cr}$ 等在单位悬浮物中, 中风浪与小风浪相比含量减少, 大风浪与中风浪相 比含量略微增加. 研究表明: (1)金属元素在水体总悬浮物中的含量主要受风浪影响,但风浪对单位悬浮物中金属含量的 影响则因元素而异; 2)除 $\mathrm{Cu} 、 \mathrm{Mn} 、 \mathrm{Zn}$ 外,悬浮物中重金属含量随粒径增大含量减少.

关键词:太湖; 风浪扰动; 悬浮物; 重金属

\section{Effects of wind-wave disturbance on heavy metal contents in suspended solids of Lake Taihu}

CHI Qiaoqiao ${ }^{1,3}$, ZHU Guangwei $^{1 * *}$, ZHANG Zhanping $^{2} \&$ QIN Boqiang ${ }^{1}$

(1: Nanjing Institute of Geography \& Limnology, Chinese Academy of Sciences, Nanjing 210008, P. R. China)

(2: College of Environment and Resources, Zhejiang University, Hangzhou 310029, P. R. China)

(3: Graduate School of the Chinese Academy of Sciences, Beijing 100039, P. R. China)

Abstract: Surface water was taken from the east shore of the mouth of Meiliang Bay, Lake Taihu. The lake water was sampled under weak $(2 \mathrm{~m} / \mathrm{s})$, modest $(7 \mathrm{~m} / \mathrm{s})$ and strong wind- wave $(11 \mathrm{~m} / \mathrm{s})$, respectively. Suspended solids ( SS) were obtained by centrifuging $25 \mathrm{~L}$ surface water. SS were further freeze-dried and microwave digested, and the contents of $\mathrm{Co}, \mathrm{Cr}, \mathrm{Cu}, \mathrm{Ni}, \mathrm{Pb}, \mathrm{Zn}, \mathrm{Al}, \mathrm{Ca}, \mathrm{Fe}, \mathrm{Mn}$ in SS were determined by ICP-AES. It was found that the particulate metal amounts increased gradually with wind speed. Moreover, different metal contents in SS showed different variation trend with wind speed. The contents of $\mathrm{Zn}$ in SS decreased with wind speed; the contents of $\mathrm{Mn}$ and $\mathrm{Cu}$ were highest at middle wind speed; and contents of $\mathrm{Al}, \mathrm{Fe}, \mathrm{Ni}, \mathrm{Pb}, \mathrm{Co}$, Cr were lowest at the middle wind speed. These results suggested the metal contents in the shallow lake water were mainly influenced by wind-wave disturbance.

Keywords: Lake Taihu; wind-wave disturbance; suspended solids; heavy metals

风浪是由于风作用于湖面所产生的一种水质点周期性起伏运动 ${ }^{[1]}$. 风浪所引起湖水的垂直紊动, 对湖 水理化性质的分布、湖中泥沙的输移、浮游生物的迁移以及湖水中污染物质的扩散和净化等过程均有一定 的影响 ${ }^{[1]}$. 重金属在水环境中的迁移、赋存主要以颗粒态的形式进行,水体中悬浮物含量决定着整个水体 中的重金属含量 ${ }^{[2]}$. Sheng 等认为, 浅水湖泊中沉积物的再悬浮主要是由于波浪的作用 ${ }^{[3]}$. 因此风浪扰动引

* 国家自然科学基金(40203007) 和中国科学院知识创新工程重大项目 (KZCX1 - SW - 12) 联合资助. $2005-07-27$ 收稿;2005-12-20 收修改稿. 池俏俏,女, 1979 年生, 硕士研究生.

** 通讯联系人: gwzhu@ niglas. ac. cn. 
起的沉积物再悬浮决定着水体中悬浮物的重金属含量. 目前国内对于浅水湖泊中风浪作用下沉积物再悬浮 物的影响研究主要集中在营养盐的内源释放 ${ }^{[4,5]}$ 、湖水透明度、水下光照分布 ${ }^{[6]}$ 和初级生产力的影响 ${ }^{[7,8]}$ 等. 而对于浅水湖泊中风浪扰动下悬浮物中重金属含量变化规律目前尚未有相关的研究报道. 太湖水面面 积 $2338 \mathrm{~km}^{2}$, 平均水深 $1.9 \mathrm{~m}$, 根据 Nixdorf ${ }^{[9]}$ 等提出的分类标准, 太湖属于极浅水湖泊. 本文将以太湖为例 研究风浪扰动对于水体悬浮物中重金属含量的影响.

\section{1 材料与方法}

\section{1 样品采集}

选取太湖梅梁湾口东岸处 (中国科学院太湖湖泊生态系统研究站栈桥平台附近, $31^{\circ} 24^{\prime} 1^{\prime \prime} \mathrm{N}, 120^{\circ} 12^{\prime} 3^{\prime \prime}$ E) 为采样点, 分别于 2005 年 1 月 17 日、31 日和 3 月 4 日, 相应风速分别为 $2 \mathrm{~m} / \mathrm{s} 、 7 \mathrm{~m} / \mathrm{s}$ 和 $11 \mathrm{~m} / \mathrm{s}$ 不同风浪 下进行采样. 采样时用直流洜抽取表层水 (水下约 $20 \mathrm{~cm}$ ), 经孔径为 $63 \mu \mathrm{m}$ 的尼龙网篮过滤后, 收集 $25 \mathrm{~L}$ 到 塑料桶 (该桶经 $20 \%$ 硝酸浸泡并用待收集水样荡洗两次) 中. 另外采集 $2 \mathrm{~L}$ 水样用于粒度分析. 采样后 $2 \mathrm{~h}$ 内 带回实验室进行处理. 每次取 3 个平行样.

\section{2 样品处理及测定}

将不同风浪下采集的 $25 \mathrm{~L}$ 水样全部在 5000 转/分的条件下离心 $10 \mathrm{~min}$,获取离心固体以代表水体悬浮 物. 将悬浮物样进行冷冻干燥、玛瑙研钵研细后进行金属元素测定. 取研细的样品 $0.120-0.125 \mathrm{~g}$ 放人聚四 氟乙烯消化罐, 加人浓硝酸 $4.0 \mathrm{ml}$, 盐酸 $0.5 \mathrm{ml}$, 氢氟酸 $3.0 \mathrm{ml}$ 后, 在 Berghofmws -3 微波消解系统中反应. 然后定量转人聚四氟乙烯烧杯中后, 加人 $0.5 \mathrm{ml}$ 的高氯酸, 加热蒸发干燥冷却后, 再加人 $2.5 \mathrm{ml}$ 稀硝酸 $(1$ ：1）、3-5 ml 纯水及 $0.25 \mathrm{ml}$ 双氧水, 微热冷却后, 将溶液定量转人 $25 \mathrm{ml}$ 比色管中, 定容至 $25 \mathrm{ml}$, 用 Leeman Labs Profile 电感耦合等离子体发射光谱仪 ( ICP-AES) 测定 $\mathrm{Al} 、 \mathrm{Ca} 、 \mathrm{Co} 、 \mathrm{Cr} 、 \mathrm{Cu} 、 \mathrm{Fe} 、 \mathrm{Mn} 、 \mathrm{Ni} 、 \mathrm{~Pb} 、 \mathrm{Zn}$ 等金属 元素的含量. 在数据计算中, 悬浮物中的金属含量是指单位悬浮物 (干重) 中金属的含量 $(\mathrm{mg} / \mathrm{kg})$, 单位水体 中的金属含量 $(\mathrm{mg} / \mathrm{L}$ 或 $\mu \mathrm{g} / \mathrm{L})$ 是以悬浮物中的金属含量乘以单位水体中的悬浮物含量所得.

\section{2 结果与讨论}

\section{1 不同风浪下水体中单位悬浮物的金属含量变化}

所测定单位悬浮物中 18 种元素在不同风浪条件下的含量见图 1. 可以看出在小风浪 $(2 \mathrm{~m} / \mathrm{s}) 、$ 、浪 $(7 \mathrm{~m} / \mathrm{s})$ 、大风浪 $(11 \mathrm{~m} / \mathrm{s})$ 下, 各金属元素的含量变化不同. 单位悬浮物中元素 $\mathrm{Zn}$ 在小、中、大风浪下其含量 依次减小; 与小风浪相比, 元素 $\mathrm{Al} 、 \mathrm{Fe} 、 \mathrm{Ni}$ 在中风浪下的含量减少 $11 \%-32 \%$, 与中风浪相比, 大风浪下的 含量增加 7\% - 18\%, 即在小、中、大风浪下含量先减少后增加; 与小风浪相比, 元素 $\mathrm{Cu} 、 \mathrm{Mn}$ 在中风浪下含 量分别增加 $11 \%$ 和 $191 \%$. 与中风浪相比, 大风浪下含量分别减少 $15 \%$ 和 $60 \%$, 即小、中、大风浪下含量先 增加再减少; 与小风浪相比, 在中风浪下元素 $\mathrm{Pb}$ 的含量减小 $13 \%$, 中风浪与大风浪的含量几乎相同; 与小 风浪相比,中风浪下元素 $\mathrm{Ca}$ 的含量增加 $6 \%$,在中风浪和大风浪下含量也几乎相同.
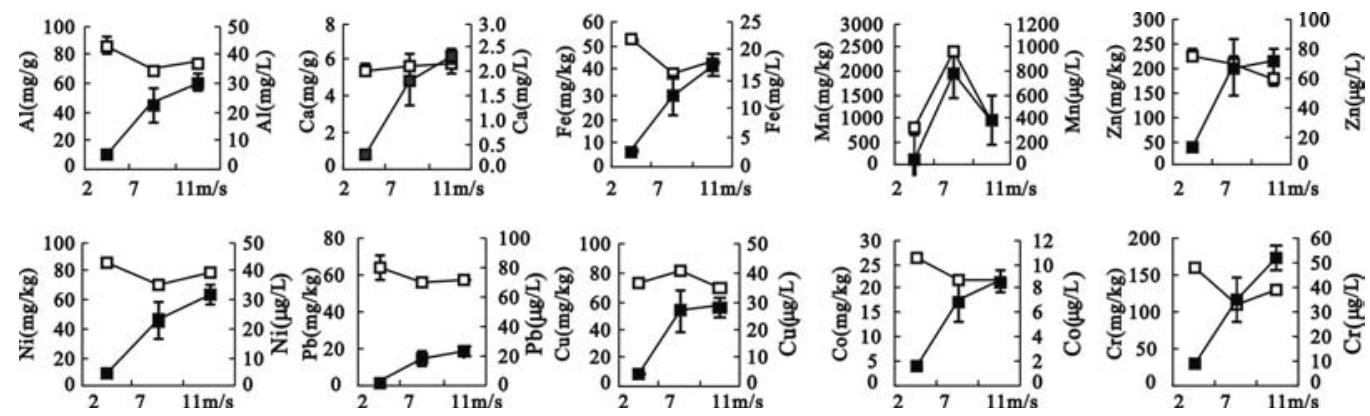

图 1 不同风浪下悬浮物中金属含量 (左轴) 和单位水体中金属含量(右轴)

Fig. 1 The heavy metals contents in SS and water under the different wind-wave disturbance 
部分金属元素在单位悬浮物中的含量和水体总悬浮物中的含量变化趋势见图 1. 水体总悬浮物中,除 $M n$ 外,其他金属元素在小、中、大风浪下的含量依次增大, 其中, 从小风浪到中风浪,含量增加幅度较大; 从 中风浪到大风浪, 含量增加幅度较小. 由不同风浪下 $25 \mathrm{~L}$ 水体悬浮物量 (图 2) 可以看出, 与小风浪相比, 中 风浪下水体总悬浮物量呈大幅度增加, 而与中风浪相比, 大风浪下总悬浮物量增幅变小,这表明金属元素在 水体总悬浮物中的含量主要受风浪和悬浮物总量的影响.

另外, 图 1 还显示, 单位悬浮物中 $\mathrm{Ca}$ 的含量随风浪增大而增加, 而 $\mathrm{Zn}$ 刚好相反. $\mathrm{Mn}$ 和 $\mathrm{Cu}$ 的变化趋势相同, 均为中风浪比小风浪含量 显著增大, 大风浪比中风浪又显著减小. 这可能是由于水体中 $\mathrm{Mn}$ 和 $\mathrm{Cu}$ 的地球化学性质相同, 有关文献也报道了 $\mathrm{Mn}$ 和 $\mathrm{Cu}$ 的相关性很好, 且 $\mathrm{Mn}$ 是亲铜元素 ${ }^{[10]}$. 元素 $\mathrm{Al} 、 \mathrm{Fe} 、 \mathrm{Ni} 、 \mathrm{~Pb} 、 \mathrm{Co} 、 \mathrm{Cr}$ 在中风浪下的含量与 小风浪相比呈减少趋势, 可能是因为中风浪扰动将表层沉积物泥沙卷 人水体和悬浮物混合 ${ }^{[11]}$, 水体中泥沙含量增加, 随着泥沙含量的增 加, 单位质量悬浮泥沙吸附重金属元素能力下降 ${ }^{[12]}$; 大风浪与中风浪 相比其含量呈小幅度增加, 主要可能是大风浪的强烈扰动使得水体中 泥沙含量减小所致.

\section{2 不同风浪下粒径组成对悬浮物中不同金属含量的影响}

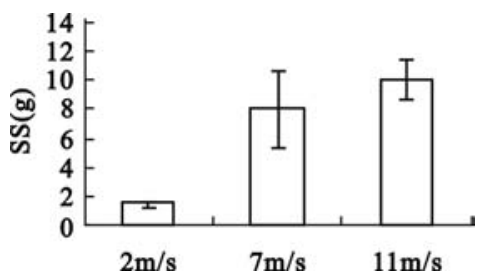

不同风浪下, 悬浮物中粒径组成情况见图 3. 小风浪下, 悬浮物的 粒径范围在 $0.32-39.81 \mu \mathrm{m}$, 中值粒径是 $4.37 \mu \mathrm{m}$, 其中 $<0.45 \mu \mathrm{m}$ 为 $0.45 \%, 0.45-63 \mu \mathrm{m}$ 为 $99.55 \%$; 中 风浪下, 粒径范围在 $0.32-363.1 \mu \mathrm{m}$, 中值粒径是 $11.09 \mu \mathrm{m}$, 其中 $<0.45 \mu \mathrm{m}$ 为 $0.39 \%, 0.45-63 \mu \mathrm{m}$ 为 $97.89 \%,>63 \mu \mathrm{m}$ 为 $1.72 \%$; 大风浪下, 粒径范围在 $0.32-69.2 \mu \mathrm{m}$, 中值粒径是 $7.83 \mu \mathrm{m}$, 其中 $<0.45 \mu \mathrm{m}$ 为 $0.45 \%, 0.45-63 \mu \mathrm{m}$ 为 $99.55 \%$. 中风浪将表层底泥含有较高活性的腐殖质悬浮起来 ${ }^{[13]}$, 由于絮凝作用 形成大分子物质,使得中风浪下粗粒径颗粒物含量最高.

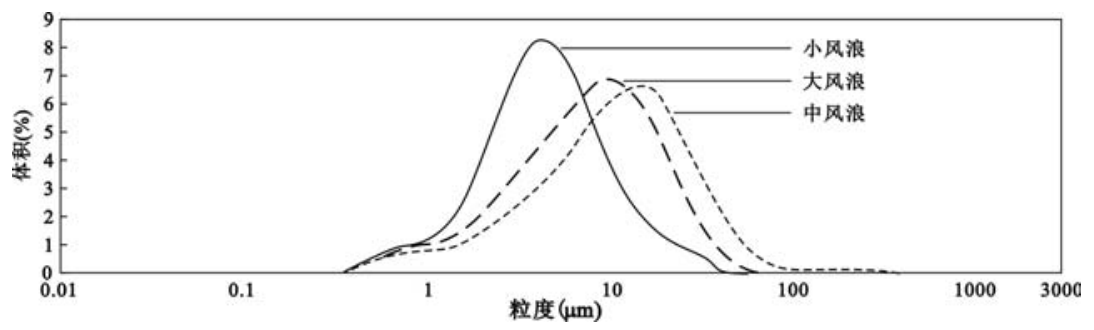

图 3 不同风浪下悬浮物中粒径组成情况

Fig. 3 Grain size compositions of suspended solids under the different wind-wave disturbance

不同风浪下悬浮物中重金属和沉积物中重金属含量分析结果 (图 4) 显示, 悬浮物中重金属含量均高于 沉积物中的含量. 悬浮物中 $\mathrm{Al} 、 \mathrm{Fe} 、 \mathrm{Ba} 、 \mathrm{Co} 、 \mathrm{~Pb} 、 \mathrm{Cr} 、 \mathrm{Ni}$ 在中风浪时含量最低, 小风浪最高, 大风浪次之; 从粒径 范围可知, 粗粒径的颗粒物在中风浪时含量最高, 小风浪最低, 大风浪高于小风浪. 表明重金属含量受颗粒 物粒径大小影响明显. 与文献认为的颗粒物粒径越小, 重金属含量越高 ${ }^{[14]}$ 观点一致. Cu、Mn 在中风浪时含 量最高, $\mathrm{Zn}$ 的含量随风浪增大逐渐降低.

\section{3 结 论}

1) 在小风浪 $(2 \mathrm{~m} / \mathrm{s}) 、$ 、中浪 $(7 \mathrm{~m} / \mathrm{s})$ 和大风浪 $(11 \mathrm{~m} / \mathrm{s})$ 下,水体总悬浮颗粒物中重金属总含量依次大 幅度增加. 单位悬浮颗粒物中各金属元素在不同风浪下含量变化不同, $\mathrm{Ca}$ 的含量在小、中、大风浪下依次增 大. $\mathrm{Zn}$ 的含量在小、中、大风浪下依次减少. $\mathrm{Mn}$ 和 $\mathrm{Cu}$ 的含量变化相同: 与小风浪相比, 中风浪下 $\mathrm{Mn} 、 \mathrm{Cu}$ 含 量显著增大, 与中风浪相比, 大风浪下含量又显著减少. 其它元素 $\mathrm{Al} 、 \mathrm{Fe} 、 \mathrm{Ni} 、 \mathrm{~Pb} 、 \mathrm{Co} 、 \mathrm{Cr}$ 等在单位悬浮物中, 中风浪与小风浪相比含量减小, 大风浪与中风浪相比含量略微增加. 

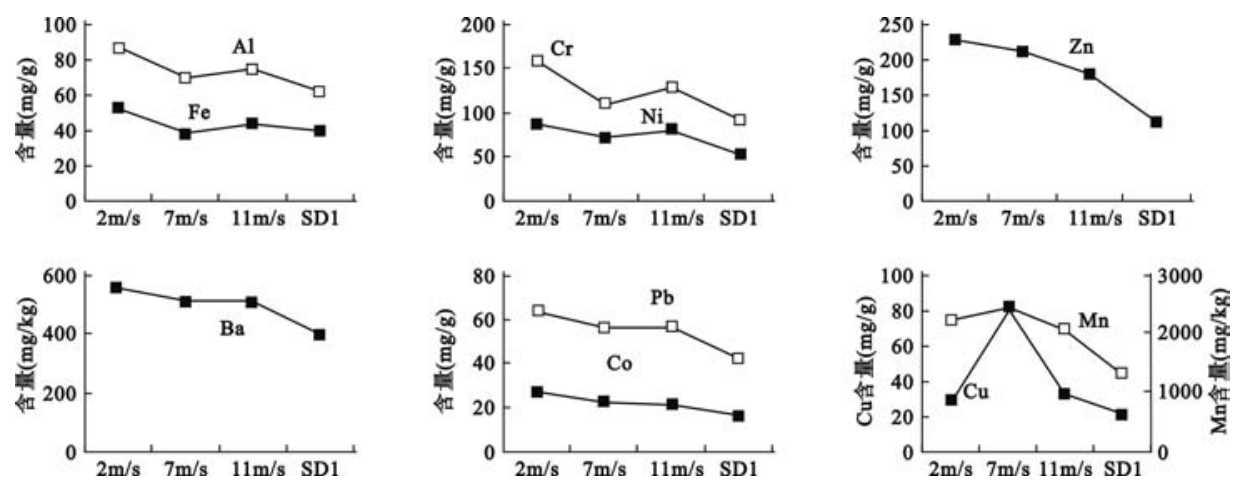

图 4 沉积物和不同风浪下悬浮物中重金属含量 ( SD1 : 表层底泥)

Fig. 4 Heavy metal contents in SS under the different wind-wave disturbance and bottom sediments

$$
\text { ( SD1: bottom sediments) }
$$

2 ) 悬浮物中粗粒径物质的含量在中风浪下最高, 小风浪最低,大风浪高于小风浪; 悬浮物中 $\mathrm{Al} 、 \mathrm{Fe} 、 \mathrm{Ba} 、$ $\mathrm{Co} 、 \mathrm{~Pb} 、 \mathrm{Cr} 、 \mathrm{Ni}$ 在中风浪下含量最低, 小风浪最高, 大风浪次之. $\mathrm{Cu} 、 \mathrm{Mn}$ 在中风浪下含量最高, $\mathrm{Zn}$ 的含量随风 浪增大逐渐降低.

致谢: 中国科学院太湖湖泊生态系统研究站钱荣树工程师野外采样给予帮助,在此表示感谢!

\section{4 参考文献}

[1] 王苏民, 窦鸿身. 中国湖泊志. 北京:科学出版社, 1998:70-73.

[2] Zhu Guangwei, Chi Qiaoqiao, Qin Boqiang. Heavy-metal contents in suspended solids of Meiliang Bay, Lake Taihu and its environmental significances. Journal of Environmental Sciences, 2005, 17(4) : 676 - 680.

[3] Sheng Y P, Lick W. The transport and resuspension of sediments in a shallow lake. Journal of Geophysical Research, 1979, 84(C4) : $1809-1826$.

[4] Zhu Guangwei, Qin Boqiang, Gao Guang. Direct evidence of phosphorus outbreak release from sediment to overlying water in a large shallow lake caused by strong wind wave disturbance. Chinese Science Bulletin, $2005, \mathbf{5 0}(6)$ : $577-582$.

[5] Qin Boqiang, Hu Weiping, Gao Guang, et al. Dynamics of sediment resuspension and the conceptual schema of nutrient release in the large shallow lake Taihu, China. Chinese Science Bulletin, 2004, 49(1) : 54 - 64 .

６］张运林, 秦伯强, 陈伟民等. 悬浮物浓度对水下光照和初级生产力的影响. 水科学进展, 2004, 15 (5) : $615-620$.

[7] Van Duin E H S, Blom G, Johannes Los F, et al. Modeling underwater light climate in relation to sedimentation, resuspension, water quality and autotrophic growth. Hydrobiologia, 2001, 444: $25-42$.

[8] Hanlon C G, Miller R L, Mcpherson B F. Relationships between wind velocity and underwater irradiance in a Shallow Lake (Lake Okeechobee, Florida, USA). Journal of the American Water Resources Association, 1998, 34(4) : $951-961$.

[9] Nixdorf B, Deneke R. Why “very shallow” lakes are more successful opposing reduced nutrient loads. Hydrobiologia, 1997, 342/343 : 269 - 284.

[10］齐风霞, 郑丙辉, 万 峻等. 渤海湾 (天津段) 柱样沉积物重金属污染研究. 海洋技术, 2004, 23(3): $85-91$.

[11] 车 越, 何 青, 吴阿娜. 河口泥沙再悬浮对悬沙中重金属元素的影响. 长江流域资源与环境, $2003, \mathbf{1 2}(5)$ : $440-444$.

[12] 蒋智勇, 程和琴, 陈吉余等. 长江口南槽底沙再悬浮对重金属吸附的影响. 安全与环境学报, 2003, 3 (3) : $36-40$.

[13] 白庆中, 宋燕光, 王 晖. 有机物对重金属在粘土中吸附行为的影响. 环境科学, 2000, 5: 64 - 67.

[14] 陈静生,王飞越, 宋吉杰等. 中国东部河流沉积物中重金属含量于沉积物主要性质的关系. 环境化学, $1996, \mathbf{1 5}(1): 8-14$. 